\title{
"Market efficiency and technical analysis during different market phases: further evidence from Malaysia"
}

\begin{tabular}{|c|c|}
\hline AUTHORS & $\begin{array}{l}\text { Safwan Mohd Nor iD https://orcid.org/0000-0003-0791-2363 } \\
\text { Guneratne Wickremasinghe }\end{array}$ \\
\hline ARTICLE INFO & $\begin{array}{l}\text { Safwan Mohd Nor and Guneratne Wickremasinghe (2017). Market efficiency and } \\
\text { technical analysis during different market phases: further evidence from } \\
\text { Malaysia. Investment Management and Financial Innovations, 14(2-2), 359-366. } \\
\text { doi:10.21511/imfi.14(2-2).2017.07 }\end{array}$ \\
\hline DOI & http://dx.doi.org/10.21511/imfi.14(2-2).2017.07 \\
\hline RELEASED ON & Monday, 21 August 2017 \\
\hline RECEIVED ON & Monday, 12 June 2017 \\
\hline \multirow[t]{2}{*}{ ACCEPTED ON } & Wednesday, 12 July 2017 \\
\hline & \begin{tabular}{|l|l|}
$(\mathrm{cc}) \mathrm{EY}_{\mathrm{E}-\mathrm{NC}}$ \\
\end{tabular} \\
\hline LICENSE & $\begin{array}{l}\text { This work is licensed under a Creative Commons Attribution-NonCommercial } 4.0 \\
\text { International License }\end{array}$ \\
\hline JOURNAL & "Investment Management and Financial Innovations" \\
\hline ISSN PRINT & $1810-4967$ \\
\hline ISSN ONLINE & $1812-9358$ \\
\hline PUBLISHER & LLC "Consulting Publishing Company "Business Perspectives" \\
\hline FOUNDER & LLC "Consulting Publishing Company "Business Perspectives" \\
\hline
\end{tabular}

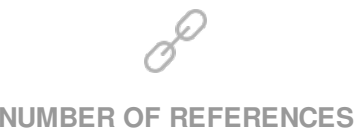

26
NUMBER OF FIGURES

0

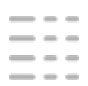

NUMBER OF TABLES

3

(C) The author(s) 2022. This publication is an open access article. 


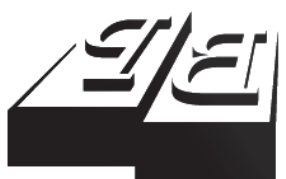

BUSINESS PERSPECTIVES

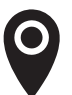

LLC "CPC "Business Perspectives" Hryhorii Skovoroda lane, 10, Sumy, 40022, Ukraine

www.businessperspectives.org

Received on: $12^{\text {th }}$ of June, 2017 Accepted on: $12^{\text {th }}$ of July, 2017

(c) Safwan Mohd Nor, Guneratne Wickremasinghe, 2017

Safwan Mohd Nor, Ph.D., CFTP, RFP, UMT Fund Manager and Senior Lecturer, School of Maritime Business and Management, University of Malaysia Terengganu, Malaysia; Research Associate, Victoria Institute of Strategic Economic Studies, Victoria University, Australia.

Guneratne Wickremasinghe, Ph.D., CA, CPA, MIPA, AFA, Senior Lecturer, College of Business, Victoria University, Australia.

\section{(ㄷ)(1) (8)}

This is an Open Access article, distributed under the terms of the Creative Commons Attribution-NonCommercial 4.0 International license, which permits re-use, distribution, and reproduction, provided the materials aren't used for commercial purposes and the original work is properly cited.
Safwan Mohd Nor (Malaysia and Australia),

Guneratne Wickremasinghe (Australia)

MARKET EFFICIENCY AND

TECHNICAL ANALYSIS DURING

DIFFERENT MARKET PHASES: FURTHER EVIDENCE FROM MALAYSIA

\begin{abstract}
The profitability of simple technical trading rules remains an interesting topic and has been thoroughly explored in the literature. In this paper, the authors investigate the profitability of two popular moving average (MA) rules in the Bursa Malaysia before, during and after the global financial crisis (GFC) of 2008-2009. Using variable length MA (VMA) and fixed length MA (FMA) technical rules, the authors explore if there were differences in their performance during the different market phases, and if swing traders can gain by trading on the basis of these strategies. When practical trading constraints are considered, the authors find that MA rules performed differently during the three market phases. Over time, the forecasting powers of these rules have diluted and they have performed poorly in the most recent subsample. The findings suggest that the Malaysian stock market is gradually becoming more efficient. This outcome can be attributed to the technological advancements and widespread use of exchange traded funds.
\end{abstract}

\section{Keywords \\ technical analysis, moving average, market efficiency, swing traders}

JEL Classification G11, G14, G17

\section{INTRODUCTION}

Market efficiency and the abnormal returns to technical trading rules are interrelated concepts in finance, where acceptance of one generally indicates rejection of the other. As a commonly used trading strategy among practitioners (see, for example, Taylor \& Allen, 1992; Wong et al., 2003), technical analysis attempts to exploit historical market patterns (price and/or volume) to yieldable normal returns by signalling entry (buy) and exit (sell) points. This action, however, is considered economically useless according to the efficient market hypothesis (EMH). The theory argues that since stock prices already reflect historical information, trading on the basis of technical rules should not consistently produce abnormal returns when the stock market is at least efficient in the weak form. Existing research, however, remains inconclusive as to whether or not the stock markets are indeed efficient (among others, see Boboc and Dinică, 2013; Metghalchi et al., 2012; Nor and Wickremasinghe, 2014; Shahzad et al., 2017b; Sobreiro et al., 2016; Urquhart and McGroart, 2016).

On the whole, technical trading rules are expected to perform differently during different market phases. For instance, Fang and $\mathrm{Xu}$ 
(2003) found that moving average (MA) rules generally dominate time series model in the US during the bull market. In addition, trading rules tend to lose their forecasting power over time due to increase in market efficiency. This has been widely documented in previous studies (see, for example, Marshall and Cahan (2005) in the New Zealand stock market and Loh (2005) in Australia). As a consequence, the global financial crisis (GFC) of 2008-2009 offers an interesting scope to test the profitability of the MA rules in recent times and consequently its practical and theoretical implications.

In this paper, we explore the trading performance of variable length MA (VMA) and fixed length MA (FMA) rules in the Bursa Malaysia before, during and after the GFC, and if swing traders (short-term traders) can profit from using those technical trading rules. This study contributes to the existing literature in the following ways. First, we employ a realistic yet straightforward long-only trading constraint. In practice, stock exchanges typically impose short-selling restrictions, and this is also the case in Bursa Malaysia, where the restricted short selling has been established. Second, we consider the profitability of the trading rules using realistic money management policy. Prior literature typically assumed no capital limitation and thus infinite amount of money can be exposed for each trade. In contrast, this study places practical limits on capital and on each trade size. Finally, whereas existing studies enforced the holding periods (for FMA rules) arbitrarily, we examine a functional interval to gauge any prospect for swing traders to earn contra gains ${ }^{1}$ in the Malaysian market.

The rest of this paper is structured as follows. Section 1 provides an overview of existing literature. Section 2 presents the data and methodology. Section 3 deals with the results and discussion. Final section concludes.

\section{A BRIEF LITERATURE SURVEY}

A number of studies have explored the profitability of MA trading rules widely regarded as the most popular form of technical analysis. Brock et al. (1992) analyzed the daily data of the Dow Jones Industry Average (DJIA) from 1897 to 1986 . They found that FMA and VMA generated profitable results that were not consistent with several stochastic processes. Using these trading rules, Bessembinder and Chan (1995) incorporated transaction costs in their analysis of six Asian markets. They observed that after deducting costs, technical rules were no longer profitable in the developed markets of Hong Kong, Japan and Korea. Nonetheless, they were still profitable in the emerging markets of Malaysia, Thailand and Taiwan. In another study, Gunasekarage and Power (2001) found that MA rules have predictive ability and outperform the returns generated by the buy-and-hold (B\&H) policy in the stock markets of Bangladesh, India, Pakistan and Sri Lanka. Lai and Lau (2006) found that these MA rules also performed well in several other Asian stock markets. Metghalchi et al. (2012) tested several forms of MA rules in the European stock markets and found that these rules can yield profit even after adjusting for data snooping biases and transaction costs. While in their study of BRICS and emerging markets, Sobreiro et al. (2016) observed that MA rules generally underperformed their B\&H counterpart.

More closely related to this study, Lai et al. (2007) examined the performance of the MA trading rules on the Kuala Lumpur Composite Index (KLCI) using data from 1977 to 1999. They found that the MA rules, specifically the 60-day VMA and FMA, provided significant profits even after accounting for costs as compared to the buy-and-hold strategy. The results appear to suggest that the Malaysian market was inefficient in the weak form during that period. Since then, Bursa Malaysia ${ }^{2}$ has undergone significant technological changes, such as the proliferation of online trading systems, and investment products, for example, exchange traded funds, to allow more efficient allocation of

1 A contra transaction occurs when traders buy and sell stocks before payment is made. The stock must be sold (or payment must be made) by the trader before $12.30 \mathrm{pm}$ at $\mathrm{t}+3$. Failure to do so will result in the position being closed (i.e., sold) by the stock broker.

2 Formerly known as the Kuala Lumpur Stock Exchange. 
capital. It remains to be seen if the market has become efficient with respect to simple technical trading rules.

\section{DATA AND METHODOLOGY}

\subsection{Data}

This study uses historical index data for the FTSE Bursa Malaysia KLCI (formerly KLCI) that spans the period 1st January 2005 to 31st December 2013, for a total of 2,226 daily observations. This period extends the previous studies by Bessembinder and Chan (1995), and Lai et al. (2007) and allows the current study to examine the profitability of the trading rules in different market phases surrounding the global financial crisis. The whole period is separated into three non-overlapping periods: (1) pre-GFC (2005-2007), (2) GFC period (20082009), and (3) post-GFC (2010-2013). We obtained historical index data from Yahoo Finance website (http://finance.yahoo.com).

\subsection{Moving average trading rules}

Two classes of MA rules examined in this paper VMA and FMA. The short-term MA denotes 3-day MA to reflect the $t+3$ settlement system used in Bursa Malaysia ${ }^{3}$. Consistent with Lai et al. (2007), the long-term MAs used in this study are 60-day, 120 -day and 180-day. Brock et al. (1992) pointed out that there is also a need to place a band around the long-term MA to avoid 'whiplash' signals that occur when both short-term and long-term MAs are close. Accordingly, trading rules with a $1 \%$ band are also tested, and these lead to the following rules being examined: $(3,60,0),(3,120,0),(3$, $180,0),(3,60,0.01),(3,120,0.01)$ and $(3,180,0.01)$. Simply put, the rules in parentheses indicate shortterm MA, long-term MA, band. For example, 3, 60, 0.01 means the trading rule uses 3 -day short-term MA, 60 -day long-term MA, and a $1 \%$ band.

The buy (sell) signals for the MA rules can be explained as follows. With a band of zero (0), the VMA rules generated a buy signal when the short-term MA exceeds the long-term MA, and vice versa. With a band of $1 \%$, the buy (sell) signal is only generated when the shortterm MA exceeds (drops below) the long-term MA by at least $1 \%$. Each trade is executed at $\mathrm{t} 0$, following trading signals that occurred at $\mathrm{t}-\mathrm{t}$. The concept for FMA is similar to VMA; however, after the buy signal occurs, the position is held for a number of days, while any sell signal(s) that occur within those days are ignored. Since Bursa Malaysia implements a $t+3$ settlement system, this study uses 3-day as the holding period to measure the trading performance for swing traders.

\subsection{Trading simulation, constraints and statistical tests}

In order to allow trading simulations to take place, a total of RM100,000 of investment capital is used. This amount is deemed reasonable, given that high number of traders in the country come from middle and high level of economic wealth (see, e.g., Isa \& Lim, 1995) and it is consistent with the requirements for several other investments in the country (e.g., Floating Rate Negotiable Instruments of Deposit). We limit each trade to only $2 \%$ of capital - in line with the limit proposed by Elder (1993) - as a risk management strategy to reduce exposure of each open position. Realistic trading costs, which include brokerage fees, clearing fees and stamp duty, are also considered and deducted from each buy (sell) transaction. These official rates are sourced from the Bursa Malaysia website (http://www.bursamalaysia.com).

Using one sample and independent samples t-tests, the efficacies of the VMA and FMA rules are determined by investigating whether their mean returns are significantly distinguishable from zero, and if they are significantly different to those yielded by the naïve buy-and-hold policy, respectively.

\section{EMPIRICAL RESULTS AND DISCUSSION}

Table 1 shows the performance of the MA rules used and that of the buy-and-hold policy for the FTSE Bursa Malaysia KLCI for the period 20052007. It can be seen from the table that VMA rules generally produced more profitable trades (with the exception of one) and positive mean returns,

3 Lai et al. (2007) used 5 days as their short-term MA to reflect the $t+5$ settlement procedure used in the Malaysian stock market during their sample period. Effective from 20 December 2000, the settlement period has been shortened to $t+3$. 
Table 1. VMA and FMA trading performance before the global financial crisis (2005-2007)

\begin{tabular}{|c|c|c|c|c|c|}
\hline \multicolumn{3}{|c|}{ Panel A. Results of VMA rules } & \multicolumn{3}{|c|}{ Panel B. Results of FMA rules } \\
\hline Technical strategy & $N>0$ & Mean return & Technical strategy & $\mathbf{N}>\mathbf{0}$ & Mean return \\
\hline \multirow{3}{*}{$\operatorname{VMA}(3,60,0)$} & \multirow{3}{*}{0.5493} & 0.43972 & \multirow{3}{*}{ FMA $(3,60,0)$} & \multirow{3}{*}{0.1800} & -0.06333 \\
\hline & & $(1.042)$ & & & $(-7.570)^{* *}$ \\
\hline & & $(1.303)$ & & & $(2.535)^{*}$ \\
\hline \multirow{3}{*}{$\operatorname{VMA}(3,60,0.01)$} & \multirow{3}{*}{0.4768} & 0.36778 & \multirow{3}{*}{ FMA $(3,60,0.01)$} & \multirow{3}{*}{0.1889} & -0.05444 \\
\hline & & $(0.896)$ & & & $(-6.171)^{* *}$ \\
\hline & & $(1.420)$ & & & $(2.519)^{*}$ \\
\hline \multirow{3}{*}{$\operatorname{VMA}(3,120,0)$} & \multirow{3}{*}{0.5333} & 0.61889 & \multirow{3}{*}{$\operatorname{FMA}(3,120,0)$} & \multirow{3}{*}{0.1339} & -0.07417 \\
\hline & & $(1.402)$ & & & $(-7.822)^{* *}$ \\
\hline & & $(1.029)$ & & & $(2.554)^{*}$ \\
\hline \multirow{3}{*}{$\operatorname{VMA}(3,120,0.01)$} & \multirow{3}{*}{0.6518} & 0.72722 & \multirow{3}{*}{ FMA $(3,120,0.01)$} & \multirow{3}{*}{0.1942} & -0.06417 \\
\hline & & $(1.542)$ & & & $(-6.916)^{* *}$ \\
\hline & & $(0.854)$ & & & $(2.537)^{*}$ \\
\hline \multirow{3}{*}{$\operatorname{VMA}(3,180,0)$} & \multirow{3}{*}{0.5513} & 0.62083 & \multirow{3}{*}{$\mathrm{FMA}(3,180,0)$} & \multirow{3}{*}{0.1680} & -0.07667 \\
\hline & & $(1.004)$ & & & $(-8.067)^{* *}$ \\
\hline & & $(0.877)$ & & & $(2.559)^{*}$ \\
\hline \multirow{3}{*}{$\operatorname{VMA}(3,180,0.01)$} & \multirow{3}{*}{0.6374} & 0.51528 & \multirow{3}{*}{ FMA $(3,180,0.01)$} & \multirow{3}{*}{0.1712} & -0.06889 \\
\hline & & $(0.937)$ & & & $(-7.837)^{* *}$ \\
\hline & & $(1.067)$ & & & $(2.545)^{*}$ \\
\hline
\end{tabular}

Notes: The table shows the mean monthly returns of trading using the FMA and VMA rules in the FTSE Bursa Malaysia KLCI before the GFC period. The figures in parentheses for each technical strategy refer to short-term MA, long-term MA, and band, respectively. The second row in column three for each strategy (in parentheses) indicates the t-statistics which test the hypothesis that the mean return produced by the strategy equals zero. The third row (in parentheses) in this column shows the $t$-statistics which test the hypothesis that the mean returns generated by the strategies equal the return obtained by the buy-and-hold. $\left.{ }^{*}{ }^{* *}\right)$ denotes statistical significance at $0.05(0.01)$ level. $\mathrm{N}>0$ shows the fraction of trades that produced profits after deducting transaction costs.

with the highest mean return from 120-day longterm MA and a $1 \%$ band. Nonetheless, they were statistically insignificant and were not different to those produced by the $\mathrm{B} \& \mathrm{H}$. Ironically, none of the FMA rules provide profitable trades. In fact, the losses from the 3-day holding period were statistically significant at $1 \%$ level and they also underperformed the B\&H strategy. Furthermore, the fractions of losing trades produced by the FMA rules were extremely high - all over $80 \%$.

The results from Table 2 (during the GFC of 20082009) tell a similar story. Briefly stated, VMA rules performed better than the FMA rules while the latter did not generate any positive mean profits. VMA rules with 60-day long-term MA (both with and without a $1 \%$ band) gained significantly and reject the null hypothesis of no excess returns during this particular period at $10 \%$ level. However, these rules, along with the rest of the VMA trading rules, were not significantly different from the simple buy-and-hold strategy. Echoing the results before the GFC, all FMA rules tested suffer significant losses and the returns were also significantly different from those produced by the $\mathrm{B} \& \mathrm{H}$.

In Table 3, results for the most recent subperiod (2010-2013) are provided. The most striking findings from the data is that there is a clear trend of decreasing returns and fractions of profitable trades following the GFC period for both VMA and FMA rules. All of the FMA rules explored in this study suffered significant losses (at 1\% level), while two of the VMA rules sustained similar results (statistically significant at $5 \%$ level). Overall, less than $50 \%$ of VMA trades became profitable, while FMA performed worse where all but one of the rules suffered over $90 \%$ of losing trades during the period. 
Table 2. VMA and FMA trading performance during the global financial crisis (2008-2009)

\begin{tabular}{|c|c|c|c|c|c|}
\hline \multicolumn{3}{|c|}{ Panel A. Results of VMA rules } & \multicolumn{3}{|c|}{ Panel B. Results of FMA rules } \\
\hline Technical strategy & $\mathbf{N}>\mathbf{0}$ & Mean return & Technical strategy & $\mathbf{N}>\mathbf{0}$ & Mean return \\
\hline \multirow{3}{*}{$\operatorname{VMA}(3,60,0)$} & \multirow{3}{*}{0.6328} & 0.78958 & \multirow{3}{*}{ FMA $(3,60,0)$} & \multirow{3}{*}{0.2245} & -0.03083 \\
\hline & & $(1.883)^{*}$ & & & $(-3.266)^{* * *}$ \\
\hline & & $(-0.908)$ & & & $(-0.274)$ \\
\hline \multirow{3}{*}{$\operatorname{VMA}(3,60,0.01)$} & \multirow{3}{*}{0.6842} & 0.77542 & \multirow{3}{*}{ FMA $(3,60,0.01)$} & \multirow{3}{*}{0.1522} & -0.03667 \\
\hline & & $(1.870)^{*}$ & & & $(-3.198)^{* * *}$ \\
\hline & & $(-0.898)$ & & & $(-0.269)$ \\
\hline \multirow{3}{*}{$\operatorname{VMA}(3,120,0)$} & \multirow{3}{*}{0.5827} & 0.70917 & \multirow{3}{*}{ FMA $(3,120,0)$} & \multirow{3}{*}{0.2200} & -0.02583 \\
\hline & & $(1.624)$ & & & $(-2.771)^{* *}$ \\
\hline & & $(-0.840)$ & & & $(-0.278)$ \\
\hline \multirow{3}{*}{ VMA $(3,120,0.01)$} & \multirow{3}{*}{0.5887} & 0.68292 & \multirow{3}{*}{ FMA $(3,120,0.01)$} & \multirow{3}{*}{0.1600} & -0.03333 \\
\hline & & $(1.598)$ & & & $(-2.949)^{* * *}$ \\
\hline & & $(-0.822)$ & & & $(-0.272)$ \\
\hline \multirow{3}{*}{$\operatorname{VMA}(3,180,0)$} & \multirow{3}{*}{0.4873} & -0.01875 & \multirow{3}{*}{ FMA $(3,180,0)$} & \multirow{3}{*}{0.1475} & -0.04500 \\
\hline & & $(-0.032)$ & & & $(-4.908)^{* * *}$ \\
\hline & & $(-0.255)$ & & & $(-0.262)$ \\
\hline \multirow{3}{*}{$\operatorname{VMA}(3,180,0.01)$} & \multirow{3}{*}{0.4873} & -0.03750 & \multirow{3}{*}{ FMA $(3,180,0.01)$} & \multirow{3}{*}{0.2167} & -0.03917 \\
\hline & & $(-0.064)$ & & & $(-3.661)^{* * *}$ \\
\hline & & $(-0.241)$ & & & $(-0.267)$ \\
\hline
\end{tabular}

Notes: The table shows the mean monthly returns of trading using the FMA and VMA rules in the FTSE Bursa Malaysia KLCI during the GFC period. The figures in parentheses for each technical strategy refer to short-term MA, long-term MA, and band, respectively. The second row in column three for each strategy (in parentheses) indicates the t-statistics which test the hypothesis that the mean return produced by the strategy equals zero. The third row (in parentheses) in this column shows the $\mathrm{t}$-statistics which test the hypothesis that the mean returns generated by the strategies equal the return obtained by the buy-and-hold. ${ }^{*},{ }^{* *}$ and ${ }^{* * *}$ denote statistical significance at $0.10,0.05$ and 0.01 levels, respectively. $\mathrm{N}>0$ shows the fraction of trades that produced profits after deducting transaction costs.

The results convey several important messages. First, it seems that swing traders who wish to profit via contra trading may be ill-advised to do so using the FMA rules. While selling the stocks using exit signals generated by the MAs appears to be reasonable, none of the VMA rules provided significant excess returns in the third subsample. Short-term traders may have to hold their stocks longer and thus cannot yield contra gains.

Second, the Malaysian stock market appears to become more efficient in recent times and this is consistent with the findings by Loh (2005) and Marshall and Cahan (2005) in other markets. This paper offers two possible explanations for this. First, due to the technological advancements of online trading facilities in the Bursa Malaysia, quicker access to market data and plac- ing trading orders are possible, which result in a more liquid market and therefore better market efficiency. Second, the improvement in market efficiency can also be contributed to the popularity of exchange traded funds (ETFs) in Malaysia, such as the FTSE Bursa Malaysia KLCI ETF and MyETF Dow Jones Islamic Market Malaysia Titans 25. As documented by Hsu et al. (2010), the predictive ability of technical trading rules diminished in several stock markets after ETFs were introduced, since their tradability and low trading cost resulted in an increase in market liquidity, which in turn led to an increase in informational efficiency. Overall, the results in this study compliment and extend earlier findings by Bessembinder and Chan (1995) and Lai et al. (2007) for Malaysia, and suggest that these simple technical trading rules may no longer be viable strategies in this market. 
Table 3. VMA and FMA trading performance after the global financial crisis (2010-2013)

\begin{tabular}{|c|c|c|c|c|c|}
\hline \multicolumn{3}{|c|}{ Panel A. Results of VMA rules } & \multicolumn{3}{|c|}{ Panel B. Results of FMA rules } \\
\hline Technical strategy & $\mathbf{N}>\mathbf{0}$ & Mean return & Technical strategy & $\mathbf{N}>\mathbf{0}$ & Mean return \\
\hline \multirow{3}{*}{$\operatorname{VMA}(3,60,0)$} & \multirow{3}{*}{0.3396} & -0.13333 & \multirow{3}{*}{ FMA $(3,60,0)$} & \multirow{3}{*}{0.0699} & -0.07375 \\
\hline & & $(-0.717)$ & & & $(-11.992)^{* * *}$ \\
\hline & & $(2.143)^{* *}$ & & & $(2.215)^{* *}$ \\
\hline \multirow{3}{*}{$\operatorname{VMA}(3,60,0.01)$} & \multirow{3}{*}{0.3995} & -0.12792 & \multirow{3}{*}{ FMA $(3,60,0.01)$} & \multirow{3}{*}{0.0619} & -0.06188 \\
\hline & & $(-0.670)$ & & & $(-9.411)^{* * *}$ \\
\hline & & $(2.120)^{* *}$ & & & $(2.185)^{* *}$ \\
\hline \multirow{3}{*}{$\operatorname{VMA}(3,120,0)$} & \multirow{3}{*}{0.3671} & 0.00167 & \multirow{3}{*}{$\operatorname{FMA}(3,120,0)$} & \multirow{3}{*}{0.0649} & -0.07792 \\
\hline & & $(0.007)$ & & & $(-11.970)^{* * *}$ \\
\hline & & $(1.710)^{*}$ & & & $(2.225)^{* *}$ \\
\hline \multirow{3}{*}{$\operatorname{VMA}(3,120,0.01)$} & \multirow{3}{*}{0.5194} & 0.06333 & \multirow{3}{*}{ FMA $(3,120,0.01)$} & \multirow{3}{*}{0.0597} & -0.07083 \\
\hline & & $(0.235)$ & & & $(-9.754) * * *$ \\
\hline & & $(1.549)$ & & & $(2.207)^{* *}$ \\
\hline \multirow{3}{*}{$\operatorname{VMA}(3,180,0)$} & \multirow{3}{*}{0.5987} & 0.18042 & \multirow{3}{*}{ FMA $(3,180,0)$} & \multirow{3}{*}{0.0745} & -0.08229 \\
\hline & & $(0.621)$ & & & $(-12.236)^{* * *}$ \\
\hline & & $(1.273)$ & & & $(2.236)^{* *}$ \\
\hline \multirow{3}{*}{$\operatorname{VMA}(3,180,0.01)$} & \multirow{3}{*}{0.4873} & 0.38750 & \multirow{3}{*}{ FMA $(3,180,0.01)$} & \multirow{3}{*}{0.2167} & -0.08188 \\
\hline & & $(1.301)$ & & & $(-11.804)^{* * *}$ \\
\hline & & $(0.845)$ & & & $(2.235)^{* *}$ \\
\hline
\end{tabular}

Notes: The table shows the mean monthly returns of trading using the FMA and VMA rules in the FTSE Bursa Malaysia KLCI after the GFC period. The figures in parentheses for each technical strategy refer to short-term MA, long-term MA, and band, respectively. The second row in column three for each strategy (in parentheses) indicates the t-statistics which test the hypothesis that the mean return produced by the strategy equals zero. The third row (in parentheses) in this column shows the t-statistics which test the hypothesis that the mean returns generated by the strategies equal the return obtained by the buy-and-hold. ${ }^{*}{ }^{* *}$ and ${ }^{* * *}$ denote statistical significance at $0.10,0.05$ and 0.01 levels, respectively. $N>0$ shows the fraction of trades that produced profits after deducting transaction costs.

\section{CONCLUSION AND IMPLICATIONS}

This paper investigates the profitability of variable length moving average and fixed length moving average rules - the two most popular and simplest forms of technical trading rules - during the periods before, during and after the global financial crisis, in Bursa Malaysia. We find that there were indeed differences in the trading performance during the three subsample periods.

On the whole, the profitability of these rules decline over time. With the presence of practical trading constraints, the MA rules made popular by Brock et al. (1992) can no longer offer significant profitable returns in the Malaysian stock market. Swing traders, in particular, will not be able to earn short-term gains using these simple trading strategies. All in all, the results seem to point towards the fact that Bursa Malaysia is gradually becoming weak-form efficient. This finding is likely due to the innovations in technology and also increasingly pervasive use of exchange traded funds. Note however that the Malaysian market might not be fully efficient. For example, Nor and Islam (2016) observed that simple portfolio diversification rule underperforms a naïve $(1 / \mathrm{N})$ allocation policy. Indeed, Shahzad et al. (2017b) showed that even a developed market such as the U.S. may not be entirely efficient.

Accordingly, future studies can explore potential market inefficiency exploitation by utilizing more refined trading rules such as the moving average convergence divergence (MACD) and relative strength index (RSI) used by Chong et al. (2014) and Nor and Wickremasinghe (2014) to reveal if they can still earn traders abnormal returns (after adjusting for costs and risks) in emerging markets. The utilization of sophisticated modelling techniques to capture nonlinearity including artificial neural networks (for 
instance, Vanstone \& Finnie, 2009), exploration into macroeconomic determinants and/or causality of different markets to stock returns (e.g., Acikalin et al., 2008; Shahzad et al., 2017a) and consequently formulating trading rules, or profitability of simple fundamental screening procedures (see Aby et al., 2001), can similarly be investigated.

\section{REFERENCES}

1. Aby, C. D., Briscoe, N. R., Elliott, R. S., \& Bacadayan, A. (2001). Value stocks: a look at benchmark fundamentals and company priorities. Journal of Deferred Compensation, 7(1), 20-31. Retrieved from https://search. proquest.com/openview/75ecf879 3401c4f359d1f8d72f29f40c

2. Acikalin, S., Aktaş, R., \& Unal, S. (2008). Relationships between stock markets and macroeconomic variables: an empirical analysis of the Istanbul Stock Exchange. Investment Management and Financial Innovations, 5(1), 8-16. Retrieved from https://businessperspectives.org/journals/ investment-management-and-financial-innovations/issue-70/ relationships-between-stock-markets-and-macroeconomic-variables-an-empirical-analysis-of-the-istanbul-stock-exchange

3. Bessembinder, H., \& Chan, K. (1995). The profitability of technical trading rules in the Asian stock markets. Pacific-Basin Finance Journal, 3(2-3), 257-284. https://doi.org/10.1016/0927538X(95)00002-3

4. Boboc, I. A., \& Dinică, M. C (2013). An algorithm for testing the efficient market hypothesis. PLOS ONE, 8(10), e78177. https://doi.org/10.1371/journal. pone. 0078177

5. Brock, W., Lakonishok, J., \& LeBaron, B. (1992). Simple technical trading rules and the stochastic properties of stock returns. Journal of Finance, 47(5), 1731-1764. https://doi. org/10.1111/j.1540-6261.1992. tb04681.x

6. Chong, T. T. L., Ng, W. K., \& Liew, V. K. S. (2014). Revisiting the performance of MACD and RSI oscillators. Journal of Risk and Financial Management, 7(1), 1-12. https://doi.org/10.3390/ jrfm7010001

7. Elder, A. (1993). Trading for a living: psychology, trading tactics, money management. New York: John Wiley and Sons.

8. Fama, E. F. (1970). Efficient capital markets: a review of theory and empirical work. Journal of Finance, 25(2), 383-417. https:// doi.org/10.1111/j.1540-6261.1970. tb00518.x

9. Fang, Y., \& Xu, D. (2003). The predictability of asset returns: an approach combining technical analysis and time series forecasts. International Journal of Forecasting, 1, 369-385 https://doi.org/10.1016/S01692070(02)00013-4

10. Gunasekarage, A., \& Power, D. M. (2001). The profitability of moving average trading rules in South Asian stock markets. Emerging Markets Review, 2(1), 17-33. https://doi.org/10.1016/S15660141(00)00017-0

11. Hsu, P. H., Hsu, Y. C., \& Kuan, C. M. (2010). Testing the predictive ability of technical analysis using a new stepwise test without data snooping bias. Journal of Empirical Finance, 17, 471-484. https://doi.org/10.1016/j. jempfin.2010.01.001

12. Isa, M. M., \& Lim, C. F. (1995). Profile of individual investors in the Kelang Valley area. Capital Markets Review, 3(1), 1-15. Retrieved from http:// www.mfa.com.my/wp-content/uploads/2015/11/vol-3no1-1995-1-15.pdf

13. Lai, M. M., \& Lau, S. H. (2006) The profitability of the simple moving averages and trading range breakout in the Asian stock markets. Journal of Asian
Economics, 17(1), 144-170. https://doi.org/10.1016/j.asieco.2005.12.001

14. Lai, M. M., Balachandher, K. G., \& Nor, F. M. (2007). An examination of the random walk model and technical trading rules in the Malaysian stock market. Malaysian Accounting Review, 6(2), 99-121. Retrieved from http:// arionline.uitm.edu.my/ojs/index. $\mathrm{php/MAR/article/view/514}$

15. Loh, E. Y. L. (2005). A comparative study of technical trading rules, time-series trading rules and combined technical and time-series trading strategies in the Australian Stock Exchange (Doctoral thesis, The University of Western Australia). Retrieved from http:// repository.uwa.edu.au/dtl_publish/Theses/44/6762.html

16. Marshall, B. R., \& Cahan, R. H. (2005). Is technical analysis profitable on a stock market which has characteristics that suggest it may be inefficient? Research in International Business and Finance, 19(3), 384-398. https://doi. org/10.1016/j.ribaf.2005.05.001

17. Metghalchi, M., Marcucci, J., \& Chang, Y. H. (2012). Are moving average trading rules profitable? Evidence from the European stock markets. Applied Economics, 44(12), 1539-1559. https://doi.org/ 10.1080/00036846.2010.543084

18. Nor, S. M., \& Wickremasinghe, G. (2014). The profitability of MACD and RSI trading rules in the Australian stock market. Investment Management and Financial Innovations, 11(4), 194-199. Retrieved from https:// businessperspectives.org/ journals/investment-management-and-financial-innovations/ issue-4-cont-9/the-profitabilityof-macd-and-rsi-trading-rules-inthe-australian-stock-market 
19. Nor, S. M., \& Islam, S. M. N. (2016). Beating the market: can evolutionary based portfolio optimisation outperform the Talmudic diversification strategy? International Journal of Monetary Economics and Finance, 9(1), 90-99. https://doi.org/10.1504/ IJMEF.2016.074584

20. Shahzad, S. J. H., Nor, S. M., Hammoudeh, S., \& Shahbaz, M. (2017a). Directional and bidirectional causality between U.S. industry credit and stock markets and their determinants. International Review of Economics and Finance, 47, 46-61. https://doi. org/10.1016/j.iref.2016.10.005

21. Shahzad, S. J. H., Nor, S. M., Mensi, W., \& Kumar R. R. (2017b). Examining the efficiency and interdependence of US credit and stock markets through MF-
DFA and MF-DXA approaches. Physica A: Statistical Mechanics and its Applications, 471, 351-363. https://doi.org/10.1016/j.physa.2016.12.037

22. Sobreiro, V. A., Cruz Cacique da Costa, T. R., Farias Nazário, R. T., Lima e Silva, J., Moreira, E. A., Filho, M. C. L., Kimura, H., \& Arismendi Zambrano, J. C. (2016). The profitability of moving average trading rules in BRICS and emerging stock markets. The North American Journal of Economics and Finance, 38, 86-101. https://doi.org/10.1016/j.najef.2016.08.003

23. Taylor, M. P., \& Allen, H. (1992). The use of technical analysis in the foreign exchange market. Journal of International Money and Finance, 11(3), 304-314. https://doi.org/10.1016/02615606(92)90048-3
24. Urquhart, A., \& McGroarty, F. (2016). Are stock markets really efficient? Evidence of the adaptive market hypothesis. International Review of Financial Analysis, 47, 39-49. https://doi.org/10.1016/j. irfa.2016.06.011

25. Vanstone, B., \& Finnie, G. (2009) An empirical methodology for developing stock market trading systems using artificial neural networks. Expert Systems with Applications, 36(3), 66686680. https://doi.org/10.1016/j. eswa.2008.08.019

26. Wong, W. K., Manzur, M., \& Chew, B. K. (2003). How rewarding is technical analysis? Evidence from Singapore stock market. Applied Financial Economics, 13(7), 543551. https://doi.org/10.1080/09 60310022000020906 